Supplement of Hydrol. Earth Syst. Sci. Discuss., 11, 6969-6992, 2014

http://www.hydrol-earth-syst-sci-discuss.net/11/6969/2014/

doi:10.5194/hessd-11-6969-2014-supplement

(C) Author(s) 2014. CC Attribution 3.0 License.

(c) (1)

\title{
Technical Note: Reducing the spin-up time of integrated surface water- groundwater models
}

H. Ajami et al.

Correspondence to: H. Ajami (h.ajami@unsw.edu.au) 


\section{Supplementary Material}
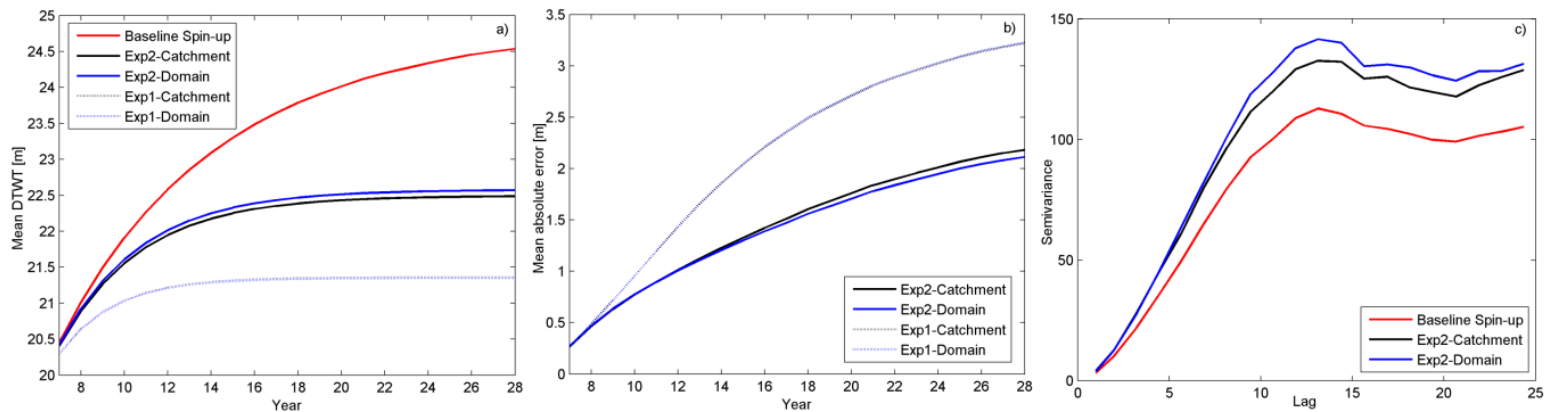

Fig. S1. a) Comparison between the simulated mean annual DTWT obtained from the baseline spin-up approach of ParFlow.CLM and empirical DTWT functions for the Baldry sub-catchment. The single exponential model was formulated using the domain and catchment averaged data from spin-up simulations 2 to 6 ; b) estimated mean absolute error based on simulated DTWT from the baseline spin-up together with both catchment and domain averaged single and double exponential functions; and c) experimental semivariograms of mean annual DTWT from ParFlow.CLM equilibrium year (after 28 years of simulations) and DTWT from catchment and domain averaged double exponential functions. DTWT distributions from the DTWT functions had higher variances relative to the baseline simulation. Exp1 and Exp2 refer to single and double exponential functions respectively. 

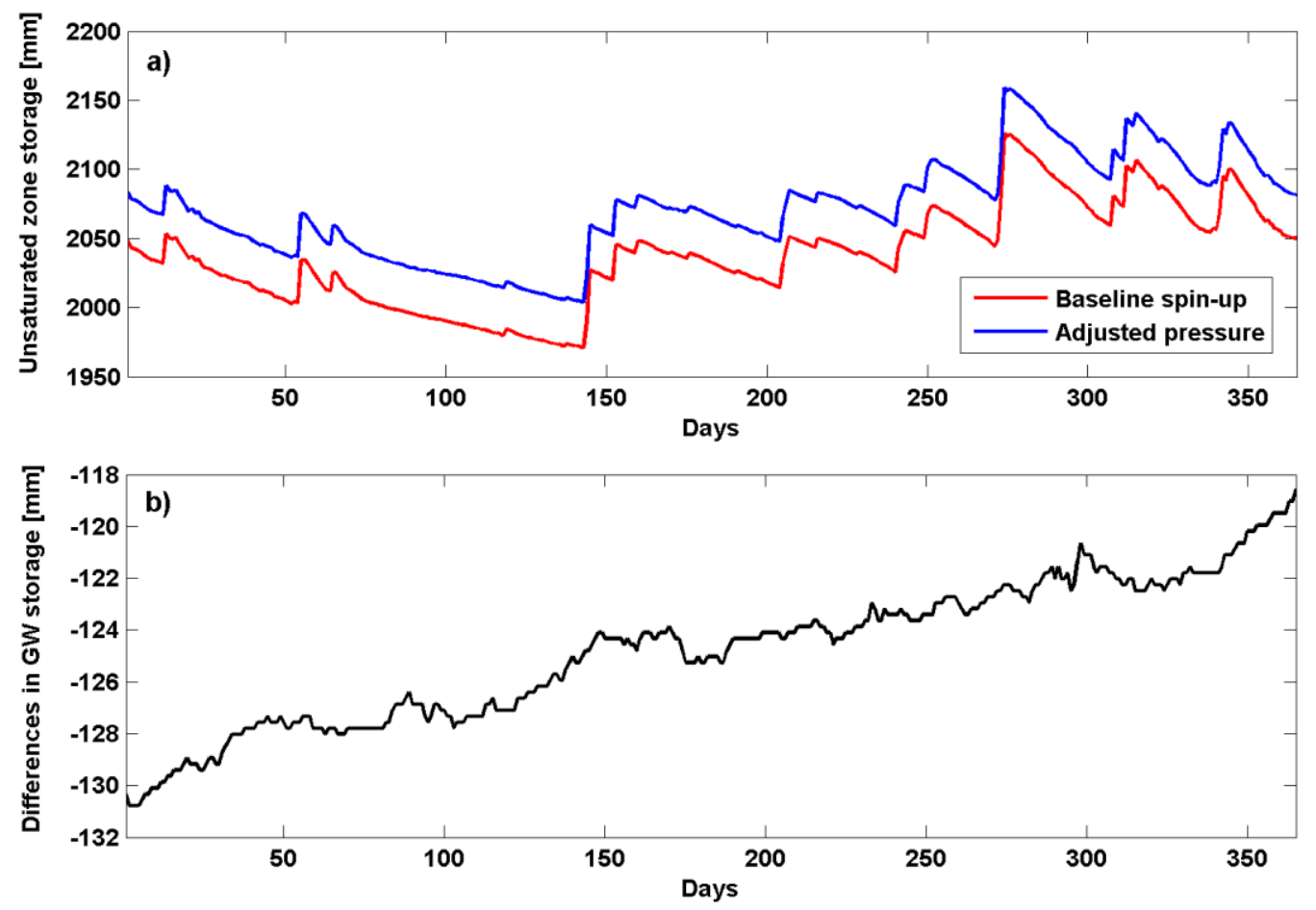

Fig. S2. a) Comparison of unsaturated zone storage dynamics of the equilibrium year obtained from the hybrid spin-up approach and the baseline spin-up simulations in Baldry sub-catchment. b) differences in groundwater storages of the equilibrium year obtained from the baseline spin-up simulation and the hybrid approach. 